\title{
CAPÍTULO 49: QUALIDADE MICROBIOLOGICA DO LEITE: JATROPHA DIOICA CONTRA BACTERIAS DE MASTITE BOVINA
}

\section{CHAPTER 49: MICROBIOLOGICAL QUALITY OF MILK: JATROPHA DIOICA AGAINST BOVINE MASTITIS BACTERIA}

Patrícia da Silva Nascente ${ }^{1}$; Carolina Labrecht Gonçalves ${ }^{2}$; Giniani Carla Dors ${ }^{3}$; Jesús Jaime Hernandez Escareño ${ }^{4}$; Rafael Guerra Lund ${ }^{5}$

Resumo

O leite é um produto altamente perecível e suas características físico-químicas e biológicas se alteram facilmente com a ação de microrganismos. Casos de mastite e má higienização no processo de ordenha possibilitam o aparecimento desses agentes. Como alternativa profilática e terapêutica, as plantas medicinais ganham espaço na medicina veterinária como opção aos tratamentos e prevenções usuais. O objetivo deste estudo foi avaliar o potencial antibacteriano do extrato alcoólico de Jatropha dioica frente a bactérias isoladas de leite de vacas com mastite. Com esse propósito, a suscetibilidade de Staphylococcus spp. e Streptococcus spp. frente a J. dioica foi verificada através da técnica de Microdiluição em Caldo. Observou-se inibição do crescimento dos isolados nas CIM de $28,12 \mu \mathrm{g} \cdot \mathrm{mL}^{-1}$ a $112,5 \mu \mathrm{g} \cdot \mathrm{mL}^{-1}$. Estes resultados sugerem potencial antimicrobiano do extrato alcoólico de $J$. dioica, caracterizando-a como promissora no tratamento e prevenção da mastite bovina e contaminação do leite.

Palavras-Chave: Atividade antimicrobiana, Plantas medicinais, Leite bovino, Staphylococcus spp., Streptococcus spp.

\begin{abstract}
Milk is highly perishable product, and its physicochemical and biological characteristics can change easily with the action of microorganisms. As a prophylactic and therapeutic alternative, medicinal plants are gaining ground in veterinary medicine as an option to the usual prevention and treatments. This study aimed to evaluate the antimicrobial activity of the alcoholic extract of Jatropha dioica against bacteria isolated from cow's milk. The susceptibility of the organisms, Staphylococcus spp. and Streptococcus spp. was verified by the Broth Microdilution technique. There was inhibition of growth compared to all isolates, with a MIC varied from $28,12 \mu \mathrm{g} \cdot \mathrm{mL}^{-1}$ to $112,5 \mu \mathrm{g} \cdot \mathrm{mL}^{-1}$. These results suggest an antimicrobial potential of the alcoholic extract $J$. dioica, characterizing it as a promising in the treatment and prevention of bovine mastitis and milk contamination.
\end{abstract}

Keywords: Antimicrobial activity, Medicinal plants, Bovine milk, Staphylococcus spp., Streptococcus spp.

\footnotetext{
${ }^{1}$ Doutora, Universidade Federal de Pelotas, pattsn@gmail.com

${ }^{2}$ Doutora, Universidade Federal de Pelotas, carolina_lamg@yahoo.com.br

${ }^{3}$ Doutora, Universidade Federal de Pelotas, dorsgi@yahoo.com.br

${ }^{4}$ Doutor, Universidade Autonoma de Nuevo Leon - Mexico, jjescareno@hotmail.com

${ }^{5}$ Doutor, Universidade Federal de Pelotas, rafael.lund@gmail.com
} 


\section{Introdução}

O leite é um dos alimentos mais nobres por ter sua composição rica em proteína, gordura, carboidratos, sais minerais e vitaminas, tendo seu consumo difundido em todo o mundo. Segundo o Art. 475 do Regulamento de Inspeção Industrial e Sanitária de Produtos de Origem Animal (RIISPOA) o 'leite é produto oriundo de ordenha completa e ininterrupta, em condições de higiene, de vacas sadias, bem alimentadas e descansadas (BRASIL, 1997).

Os parâmetros para avaliação da qualidade do leite são a composição (teores de proteína, gordura, lactose, sais minerais e vitaminas), as características físico-químicas (sabor, odor, cor, acidez, $\mathrm{pH}$, densidade, ponto de congelamento, ponto de ebulição, calor específico, tensão superficial, viscosidade e condutividade elétrica) e a higiene. Esse alimento de grande importância nutricional tem capacidade de promover multiplicação de micro-organismos e se faz necessario e imprescindível o controle e cuidado com a higiene e qualidade do produto, desde a sua produção, transporte e beneficiamento, buscando evitar danos à saúde humana, perdas nos laticínios e inocuidade do produto (GUERREIRO et al., 2005).

A mastite bovina é uma dispendiosa e multifatorial enfermidade que acomete os rebanhos leiteiros em todo o mundo, influenciando diretamente na qualidade e na produção do leite, além de promover a ocorrência de perda por descartes de animais e gastos com o tratamento curativo (HAGNESTAM-NIELSEN et al., 2009; LOPES et al., 2012; LANGONI, 2013; DEMEU et al., 2015).

Com uma conhecida pluralidade etiológica (LANGONI, 2013), a mastite apresenta os gêneros Staphylococcus spp. e Streptococcus spp. dentre os principais agentes envolvidos com a enfermidade de origem bacteriana (ACOSTA et al., 2016; FREITAS et al., 2018), caracterizando-a como um risco iminente à saúde pública ao se considerar o potencial patogênico destes micro-organismos.

Staphylococcus aureus (coagulase positiva) causa mastite clínica e subclínica em bovinos leiteiros e é um potencial problema de saúde para os seres humanos (EL ASHKER et al., 2015; FREITAS et al., 2018). Ele tem sido relatado como um dos agentes causadores mais relevantes dessa enfermidade por muitos pesquisadores (OLIVEIRA et al., 2010; LOZANO et al., 2016; EL-ASHKER et al., 2020), demonstrando a dificuldade no seu controle. A pele do úbere e tetos são os sítios onde se observa esse agente e o que facilita as infecções (ZANETTE et al., 2010).

Entretanto, Staphylococcus spp. coagulase-negativo também é conhecido como patógeno comum envolvido na mastite bovina, porém são primordialmente derivados do ambiente e geralmente são associados a uma infecção moderada (BOGNI et al., 2011). 
Streptococcus uberis também é agente causador de mastite em rebanhos leiteiros. É responsável por casos clínicos e subclínicos (HOGAN et al., 1989). Dentro do gênero Streptococcus, Streptococcus uberis é um patógeno importante na indústria de laticínios (ZADOKS, et al., 2003), visto que é um dos principais agentes causadores da mastite no mundo, incluindo o Brasil (COSTA, et al., 1998). S. uberis, assim como Escherichia coli, são considerados patógenos ambientais (RADOSTITS et al., 1994). Streptococcus dysgalactiae também está entre os mais comuns micro-organismos relacionados a mastites ambientais, que tem como principal reservatório o ambiente onde a vaca vive, não limitando-se apenas a locais onde é realizada a ordenha (SMITH \& HOGAN, 1993; OLIVER, 1988; TODHUNTER et al., 1995).

Nos exemplos citados deve-se dar ênfase especial ao caráter zoonótico dos microorganismos e também a resistência adquirida frequentemente com o tratamento antimicrobiano convencional inadequado, o qual proporciona uma seleção de micro-organismos multirresistentes (FREITAS et al., 2018; EL-ASHKERA et al., 2020; ANTOK et al., 2020) causando também problema em saúde pública (KORB et al., 2011; VASCONCELLOS \& ITO, 2011). Segundo Brito et al. (2001), diversos estudos que tratam da suscetibilidade a antimicrobianos de patógenos da mastite bovina no Brasil, apontam para um aumento crescente no padrão de resistência. Embora ela possa ocorrer naturalmente por meio de mutações espontâneas, o uso intensivo de antimicrobianos em humanos e animais acelera o processo (WHO, 2015) e apesar da pressão para reduzir o uso de antimicrobianos em animais produtores de alimentos, os antimicrobianos ainda são importantes para a saúde animal e uma ferramenta ainda usada no controle de mastite (MIDDLETON et al., 2014).

Por outro lado, além do uso de produtos no tratamento da mastite, a desinfecção de tetos antes e após a ordenha é uma prática incorporada na rotina desses animais, como preventivos na contaminação do leite e do úbere ( $\mathrm{SCHUCH}$ et al., 2008). O uso dos desinfetantes na higienização das salas de ordenha também é de grande importância na fazenda, contribuindo para a produção de alimentos lácteos de qualidade e para a obtenção de um rebanho sadio (FONSECA; SANTOS, 2000).

O termo pré-dipping consiste na antissepsia dos tetos antes da ordenha que visa reduzir o número de bactérias neste local que possam contaminar o leite e pós-dipping é o termo utilizado para a remoção após a ordenha da película de leite que permanece no teto após a retirada do conjunto de ordenha e auxilia na prevenção de infecções neste canal (SANTOS; FONSECA, 2007). Além disso, as bactérias presente no animal e no canal do teto interferem na qualidade do leite. CBT (Contagem Bacteriana Total) é uma análise indicativa das condições 
de higiene, antes, durante e após a ordenha (PEIXOTO et al., 2016), a presença de bactérias no leite vai interferir no rendimento, sabor, odor e vida de prateleira, portanto, é de fundamental importância a refrigeração do leite logo após a ordenha e a agilidade no transporte após a coleta até a indústria de laticínios (SILVA et al., 2012). Dependendo do produto utilizado no pré e pós dipping, pode haver a presença de resíduos químicos no leite e assim como a resistência dos micro-organismos aos antibióticos, a resistência frente aos desinfectantes também são relatadas na literatura.

Neste contexto, mais recentemente outras alternativas de prevenção e tratamento (TITZE; KRÖMKER, 2020; VISSIO et al., 2020; CASTELLANI et al., 2019; CHOTIGAPA et al., 2019), como o uso de plantas medicinais, visam contribuir com a necessidade de se desenvolver novos métodos a serem aplicados na medicina veterinária na tentativa de reduzir o impacto e o uso de medicamentos sintéticos, a fim de manter a integridade do animal e do consumidor (GALDINO; DOMINGUES; LAPENNA, 2012).

Pouco descrita na literatura quanto às suas propriedades terapêuticas, Jatropha dioica é uma espécie vegetal originária do semiárido mexicano, conhecida na medicina popular mexicana como "Sangre de drago" e utilizada frente a infecções de pele e tecido subcutâneo, além de problemas odontológicos e renais (MANZANERO-MEDINA et al., 2009). Deste modo, o objetivo deste estudo foi avaliar o potencial antibacteriano do extrato alcoólico das raízes da planta Jatropha dioica, frente a bactérias isoladas de leite com diagnóstico de mastite.

\section{Material e Métodos}

\section{J. dioica}

Exemplares da planta $J$. dioica foram coletados em uma região montanhosa da cidade de Monterrey - Estado de Nuevo Leon, México. As plantas foram coletadas em sua totalidade, enroladas em papéis e embaladas em papelão. Uma amostra foi depositada e identificada por um botânico do Herbário da Universidade Federal de Pelotas (Pelotas RS Brasil). A planta foi limpa, separada de acordo com suas respectivas partes vegetais e secos à temperatura ambiente por sete dias.

Foram suspensos $18 \mathrm{~g}$ de raízes frescas de J. dioica em $200 \mathrm{~mL}$ de etanol $70 \%$ e a mistura foi deixada em repouso por $24 \mathrm{~h}$, sendo utilizado o sobrenadante para o teste de suscetibilidade antimicrobiana na concentração de 0,09 g.mL $\mathrm{mL}^{-1}$. 


\section{Isolados bacterianos}

Para a análise da suscetibilidade bacteriana frente ao extrato foram utilizados oito isolados bacterianos oriundos de diferentes casos de mastite bovina: Staphylococcus coagulase negativa ( $\mathrm{n}=3)$, Staphylococcus intermedius $(\mathrm{n}=2)$, Streptococcus uberis $(\mathrm{n}=1)$, Streptococcus dysgalactiae $(n=1)$ e Streptococcus agalactiae $(n=1)$. Todos os isolados estavam estocados no Laboratório de Micologia e Bioprospecção do Departamento de Microbiologia e Parasitologia do Instituto de Biologia da Universidade Federal de Pelotas (UFPel).

\section{Microdiluição em Caldo}

O teste foi realizado por meio da técnica de Microdiluição em Caldo padronizada pelo documento M07-A9 do Clinical and Laboratory Standards Institute (CLSI, 2006) adaptada a um fitoterápico. $\mathrm{O}$ extrato foi diluído em Muller Hinton para obter dez concentrações sucessivas (1:2) de $450 \mu \mathrm{g} \cdot \mathrm{mL}^{-1}$ a $0,87 \mu \mathrm{g} \cdot \mathrm{mL}^{-1}$.

Os inóculos foram preparados individualmente através da produção de uma suspensão na escala 0,5 de MacFarland, alcançando uma concentração final de $10^{6} \mathrm{UFC} \mathrm{mL}^{-1}$ e novamente diluidos em meio de cultivo Muller Hinton. Como controle positivo, foi adicionada apenas a suspensão bacteriana de cada espécie e o meio de cultivo Muller Hinton, sendo considerado controle negativo o meio de cultivo e as diluições do extrato etanólico.

As microplacas foram incubadas a $36^{\circ} \mathrm{C}$ e a leitura da Concentração Inibitória Mínima (CIM) foi realizada após $24 \mathrm{~h}$, quando foi comparado o crescimento de cada isolado em relação aos respectivos controles. A CIM foi considerada como a média da menor concentração capaz de inibir totalmente o crescimento bacteriano visualizado em cada duplicata.

\section{Citotoxidade}

O meio de cultura de células utilizado foi Dulbecco (DMEM), suplementado com 10\% de soro fetal bovino (FBS), $2 \%$ de glutamina, penicilina (100 $\left.\mathrm{U} \mathrm{mL}^{-1}\right)$ e estreptomicina (100 $\mathrm{mg} \mathrm{mL} \mathrm{m}^{-1}$ ). Os fibroblastos de camundongo da linha celular imortalizada 3T3 / NIH foram mantidos como cultura de estoque em DMEM e incubados a $37{ }^{\circ} \mathrm{C}$ em uma atmosfera umidificada de $5 \%$ de $\mathrm{CO}_{2}$ no ar, até subconfluência. $\mathrm{O}$ ensaio de brometo de 3-(4,5dimetiltiazol-2-il)-2,5-difeniltetrazólio (MTT) avaliou a função metabólica celular de acordo com a atividade desidrogenase mitocondrial (BEAN et al., 1995). A viabilidade celular foi analisada pelo software de análise estatística SigmaPlot 12 (Systat Software Inc., San Jose CA EUA). 


\section{Resultados e Discussão}

As CIMs observadas frente aos oito isolados estudados variaram entre $28,12 \mu \mathrm{g} \cdot \mathrm{mL}^{-1} \mathrm{a}$ $112,5 \mu \mathrm{g} . \mathrm{mL}^{-1}$. Na Tabela 1 podem-se observar os resultados de acordo com cada isolado bacteriano.

Tabela 1. Concentração Inibitória Mínima (CIM) do extrato alcoólico de Jatropha dioica observada frente a diferentes bactérias isoladas de mastite bovina.

\begin{tabular}{cc}
\hline Isolado Clínico bacteriano & $\mathrm{CIM}\left(\mu \mathrm{g} \cdot \mathrm{mL}^{-1}\right)$ \\
\hline Staphylococcus intermedius & 56,25 \\
Staphylococcus intermedius & 56,25 \\
Staphylococcus coagulase negativa & 56,25 \\
Staphylococcus coagulase negativa & 28,12 \\
Staphylococcus coagulase negativa & 28,12 \\
Streptococcus uberis & 112,5 \\
Streptococcus dysgalactiae & 56,25 \\
Streptococcus agalactiae & 56,25 \\
\hline
\end{tabular}

Fonte: Própria (2020).

O extrato alcoólico de $J$. dioica demonstrou atividade antibacteriana in vitro frente aos isolados, obtendo-se os menores valores de CIM frente a Staphylococcus coagulase negativa, grupo considerado emergente, com crescente envolvimento em casos de mastite (PYÖR ̈̈L $\ddot{\text { A }}$ TAPONEN, 2009) e descritos por Timmis e Schultz (1987) como agentes que podem apresentar infecções de longa duração e baixa taxa de cura espontânea. Mais recentemente, em episódio de mastites, Staphylococcus spp. são relatados como relevantes devido a sua alta frequência e multirresistencia com capacidade de produção de toxinas. Nesse caso, com a produção de toxina envolve-se em casos de surtos alimentares relacionadas a diferentes espécies dentro do gênero (MARIANO et al., 2007; MEHMETI et al., 2016; ACOSTA et al, 2016).

O S. uberis foi considerado o agente menos sensível ao extrato testado, o que pode estar associado a antibioticoterapia inadequada direcionada ao animal da amostra de origem para controlar a enfermidade. De acordo com Bramley e Dodd (1984) esta espécie é considerada como sendo uma das causas mais comuns de novas infecções em vacas secas, sendo de difícil controle na rotina de higienização. No cenário mundial, a freqüência desta espécie tende a ser baixa e variável (GIANNEECHINI et al., 2002; CALDERON; BI et al., 2016), entretanto, sua importância nos rebanhos pode estar subestimada, uma vez que, se observa na literatura que o diagnóstico etiológico da mastite bovina ocasionada por Streptococcus spp., em geral, limita- 
se a identificação do gênero, não sendo feita a diferenciação dentre as espécies (SANTOS et al., 2007).

O uso das plantas com finalidade terapêutica no Brasil vem aumentando há alguns anos (NASCIMENTO et al, 2000; DIORGE et al., 2015). Os efeitos de óleos ou dos extratos de plantas sobre as bactérias têm sido estudados por muitos pesquisadores no mundo todo. Entretanto, há necessidade de maior conhecimento e de uso moderado para evitar problemas quanto ao uso prolongado e indiscriminado destes produtos (ALMAGBOUL et al, 1985; DAHANUKAR; KULKARNI; REGE, 2000; IKRAM; INAMUL, 1984; IZZO et al, 1995).

Outros estudos vem sendo desenvolvidos com plantas nativas do Brasil frente a bactérias causadoras de mastite, entre eles, foi estudado óleo de semente de girassol e Castanha do Brasil, também obtendo bons resultados (FREITAS et al., 2016; OLIVEIRA et al., 2010; BEZERRA et al., 2009; DANTAS et al., 2009; SCHUCH et al., 2008). Esses estudos não tem apenas direcionamento a planta ao tratamento da mastite, mas na eliminação precoce dessas bactérias relacionadas a essa enfermidade quando encontradas no ambiente ou na pele do animal. $\mathrm{O}$ uso de produtos naturais no pré-dipping têm por objetivo reduzir a carga microbiana presente na pele dos tetos e a obtenção de um produto sem agentes contaminantes.

Quanto a espécie $J$. dioica, não foram encontrados estudos relacionados ao uso no tratamento e prevenção de mastite, entretanto, estudos conduzidos por Silva-Belmares et al. (2014), a partir de diferentes extratos orgânicos de suas raízes, demonstraram atividade frente as bacterias Bacillus cereus, Escherichia coli, Salmonella typhi, Staphylococcus aureus, Enterobacter aerogenes, Enterobacter cloacae, Salmonella typhimurium e aos fungos Cryptococcus neoformans, Candida albicans, Candida não albicans e Sporothrix schenckii de interesse medico veterinario. Nessa pesquisa, a atividade do extrato hexano de $J$. dioica pode ser atribuída em parte à presença de $\beta$-sitosterol, o principal composto identificado por bioautografia.

Oliveira et al. (2013), verificaram a atividade anti-Candida do seu extrato, aquoso e etanólico, obtendo inibição da levedura na concentração de $28,1 \mu \mathrm{g} \cdot \mathrm{mL}^{-1}$, resultados que sustentam os obtidos no presente estudo. Não-C. albicans, o MIC e o MFC foram de 28,12 $\mu \mathrm{g} . \mathrm{mL}^{-1}$, mas para Candida famata e Candida glabrata esses valores aumentam para 56,25 $\mu \mathrm{g} \cdot \mathrm{mL}^{-1}$.

Vargas-Segura et al. (2019) verificaram à atividade bactericida contra S. mutans cariogênica ATCC 25175, bem como para a caracterização fitoquímica dessa planta entre outras 14 estudadas e concluindo que extratos selecionados são bons candidatos a serem utilizados no controle de bactérias cariogênicas. Silva-Mares et al. (2013) estudaram a planta mexicana 
contra o HSV-1 e HSV-2 e segundo descrevem que o extrato de $J$. dioica não mostrou citotoxicidade nas concentrações utilizadas.

A utilização de extratos vegetais com ação antimicrobiana foi demonstrada com eficiência em testes in vitro e in vivo na anti-sepsia de tetos antes e após a ordenha, embasando estudos que visam a promoção à integridade do animal e da qualidade do leite a partir de antimicrobianos alternativos (SCHUCH et al., 2008; AVANCINI; WIEST, 2008; FACCIN et al., 2016). Devido as suas características na medicina popular mexicana, Jatropha spp. está sendo alvo de estudos por pesquisadores brasileiros devido seu potencial medicinal, o qual pode ser atribuído por seus componentes químicos, com destaque aos alcalóides, triterpernos e esteróides (MARTINÉZ et al., 2014). No Brasil, observa-se grande variedade de estudos que avaliam diferentes características e comportamentos deste gênero, entre outros, no bioma da Caatinga, semiárido brasileiro (NEVES et al., 2010; NEVES et al., 2011; CHAVES et al., 2010; OLIVEIRA et al., 2010).

Vários artigos já foram publicados para relatar o uso medicinal não antimicrobiano de J. dioica (MARTÍNEZ et al., 2014). CREFAL (1988) cita o uso da planta em doenças como: hemorroidas, úlcera, gastrite, asma, queda de cabelo, manchas em pele, acne, sangramento de gengivas e dor de dente, entre outros. Pérez-Escandón et al. (2003) menciona o uso medicinal e comestível de J. dioica. Para o teste de citotoxicidade em relação aos extratos radiculares de J. dioica, a CIM de 28,1 $\mu \mathrm{g} \cdot \mathrm{mL}^{-1}$ foi a menos citotóxica. Araujo-Espino et al. (2017) observou, em estudo in vivo, que $J$. dioica não exerce efeito genotóxico nem citotóxico no sangue periférico quando administrado em altas doses de camundongos.

Outras espécies do gênero Jatropha são estudadas quanto as suas propriedades terapêuticas, dentre elas, J. multifida, J. gossypifolia, J. isabellei, às quais estão associadas com a atividades antibacteriana, larvicida, antioxidante, antinociceptiva e anti-inflamatória (RAMPADARATH; PUCHOOA; RANGHOO-SANMUKHIYA, 2014; OKOH et al., 2016; SILVA et al., 2013).

A relevância das pesquisas com produtos naturais e os resultados obtidos com J. dioica, justificam novas análises microbiológicas do extrato, incluindo estudos in vivo, para seu desenvolvimento como antimicrobiano alternativo.

\section{Conclusões}

Foi observado inibição do crescimento dos isolados de Staphylococcus spp. e Streptococcus spp. nas CIM de $28,12 \mu \mathrm{g} \cdot \mathrm{mL}^{-1}$ a $112,5 \mu \mathrm{g} \cdot \mathrm{mL}^{-1}$, respectivamente. Estes resultados sugerem que o extrato alcoólico da Jatropha dioica tem potencial antibacteriano 
frente a bactérias causadoras de mastite e assim pode-se considerar a planta J. dioica como promissora para o uso na produção de leite, seja no uso para tratamento e prevenção da mastite bovina como na contaminação do leite utilizado para o consumo humano.

\section{Referências}

ACOSTA, A. C.; SILVA, L. B. G.; MEDEIROS, E. S.; PINHEIRO-JÚNIOR, J. W.; MOTA, R. A. Mastites em ruminantes no Brasil. Pesquisa Veterinária Brasileira, v. 36, n. 7, p. 565 573, 2016.

ARAUJO-ESPINO, D. I.; ZAMORA-PEREZ, A. L.; ZÚÑIGA-GONZÁLEZ, G. M.; et al. Genotoxic and cytotoxic evaluation of Jatropha dioica Sessé ex Cerv. by the micronucleus test in mouse peripheral blood. Regulatory Toxicology and Pharmacology: RTP, v. 86, p. 260264, 2017.

ANTOK, F. I.; MAYRHOFER, R.; MARBACH, H.; MASENGESHO, J. C.; KEINPRECHT, H.; NYIRIMBUGA, V.; FISCHER, O.; LEPUSCHITZ, S.; RUPPITSCH, W.; EHLINGSCHULZ, M.; FEßLER, A. T.; SCHWARZ, S.; MONECKE, S.; EHRICHT, R.; GRUNERT, T.; SPERGSER, J.; LONCARIC, I. Characterization of Antibiotic and Biocide Resistance Genes and Virulence Factors of Staphylococcus Species Associated with Bovine Mastitis in Rwanda. Antibiotics, v.9, n.1, p.1-17, 2020

ALMAGBOUL, A. Z.; BASHIR, A. K.; FAROUK, A.; SALIH A. K. M. Antimicrobial activity of certain Sudanese plants used in folkloric medicine. Screening for antibacterial activity. Fitoterapia, v. 56, p. 331-337, 1985.

AVANCINI, C.; WIEST, J. M.; DALL'AGNOL, R.; HAAS, J. S.; VON POSER, G. L. Antimicrobial activity of plants used in the prevention and control of bovine mastitis in Southern Brazil. Latin American Journal of Pharmacy, v. 27, n. 6, p. 894-9, 2008.

BI, H.; DUARTE, C. M.; BRITO, M.; VILAS-BOAS, V.; CARDOSO, S.; FREITAS, P. Performance enhanced UV/vis spectroscopic microfluidic sensor for ascorbic acid quantification in human blood. Biosensors and Bioelectronics, v. 85, p. 568-572, 2016.

BOGNI, C. E outros. Waragainstmastitis: Current concept son controlling bovine mastitis pathogens. In Science against Microbial Pathogens: Communicafing. Current Research and Technological Advances, Ed. World Scientific: Singapore, p. 483-494, 2011.

BEZERRA D. A. C., PEREIRA A. V., LÔBO K. M. S., RODRIGUES O. G., ATHAYDE A. C. R., MOTA R A. et al . Atividade biológica da jurema-preta (Mimosa tenuiflora (Wild) Poir.) sobre Staphylococcus aureus isolado de casos de mastite bovina. Revista Brasileira farmacognosia, v.19, n. 4 p.814-817, 2009.

BRAMLEY, A. J.; DODD, F. H. Reviews of the progress of dairy science: mastitis controlprogress and prospects. Journal of Dairy Research, v. 51, n. 3, p. 481-512, 1984.

BRASIL, Ministério da Agricultura. Departamento Nacional de Inspeção de Produtos de Origem Animal. Regulamento da Inspeção Industrial e Sanitária de Produtos de Origem 
Animal - RIISPOA. Aprovado pelo decreto n 30691 de 29 de março de 1952. Alterado pelo Decreto 2244 de 04 de junho de 1997. Brasília - DF. 1997.

BRITO, M.A.V.P.; BRITO, J.R.F.; SILVA, M.A.S.; CARMO, R.A. Concentração mínima inibitória de dez antimicrobianos para amostras de $\mathrm{S}$. aureus isoladas de infecção intramamária bovina. Arquivos Brasileiros de Medicina Veterinário e Zootecnia, v.53, n.5, p.10-17, 2001.

CALDERÓN, A.; RODRÍGUEZ, V. C. Prevalencia de mastitis bovina y su etiología infecciosa en sistemas especializados en producción de leche en el altiplano cundiboyacense (Colombia). Revista Colombiana de Ciencias Pecuarias, v. 21, n. 4, p. 582-589, 2008.

CASTELANI, J. R. P.; ARCARO, J. E. P.; BRAGA, A. S.; BOSSO, Q.; MOURA, F.; ESPOSITO, I. P.; SAUTER, M.; CORTEZ, N.; LINCOPAN, N. Short communication: Activity of nisin, lipid bilayer fragments and cationic nisin-lipid nanoparticles against multidrugresistant Staphylococcus spp. isolated from bovine mastitis Journal of Dairy Science, v. 102, n. 1, p.678-683, 2019.

CHAVES, L.H.G.; MESQUITA, E.F.; ARAUJO, D.L.; FRANÇA, C.P. Crescimento, distribuição e acúmulo de cobre e zinco em plantas de pinhão-manso. Revista Ciência Agronômica, v. 41, n. 2, p. 167-176, 2010.

CHOTIGAPA, R.; LAMPANG, K. N.; PIKULKAEW, S.; OKONOGI, S.; SILMAN, P.; MEKTRIRAT, R. Antiseptic effect of natural teat dip containing lactic acid against mastitiscausing Escherichia coli Veterinary World v.12, p. 398-401, 2019.

CLSI. 23 M2a9. Clinical and Laboratory Standards Institute. http://www.microbiolabbg.com/CLSI.pdf, 2006.

COSTA, E.O.; RIBEIRO, A.R.; WATANABE, E.T.; MELVILLE, P.A. Infectious bovine mastitis caused by environmental organisms. Zentralbl Veterinarmed v.45, p. 65-71, 1998.

CREFAL. Manual de Homeopatía. Cuaderno de trabajo No. 9. Proyecto Especial OEA-92, Meseta purépecha, coedición Secretaría de Agricultura y Recursos Hidráulicos SARH Organización de los Estados Americanos OEA - CREFAL, Ciudad de México, México. 1988.

DAHANUKAR, S. A.; KULKARNI, R. A.; REGE, N. N. Pharmacology of medicinal plants and natural products. The Indian Journal of Pharmacology, v. 32, p. 81-118, 2000.

DANTAS, S. A. F.; SENA, L. V. T.; MELO, D. J. A.; DUARTE, F. T.; HOLOS, A. S. C.; et al. Avaliação de plantas medicinais no combate a mastite bovina. Holos, v. 4, 2009.

DEMEU, F. A.; LOPES, M. A.; ROCHA, C. M. B. M.; COSTA, G. M.; SANTOS, G.; NETO, A. F. Influência da escala de produção no impacto econômico da mastite em rebanhos bovinos leiteiros. Revista Ceres, v. 62, n. 2, p. 167-174, 2015.

MARMITT, D.; REMPEL, C.; GOETTERT, M; SILVA, A. Plantas com potencial antibacteriano da relação nacional de plantas medicinais de interesse no sistema único de saúde: revisão sistemática. Revista de Saúde Pública de Santa Catarina, v. 8, n. 2, p. 135-152, 2015 
MARICATO, E.; SANTOS, P.; BRITO, M. A. V. P.; LANGE, C.; BRITO, J. R. F.; CERQUEIRA, M. M. O. P. Streptococcus e gêneros relacionados como agentes etiológicos de mastite bovina. Acta Scientiae Veterinariae, v. 35, n. 1, p. 17-27, 2007.

EL-ASHKER, M.; GWIDA, M.; TOMASO, H.; MONECKE, S.; EHRICHT, R.; ELGOHARY, F.; HOTZEL, H.; Staphylococci in cattle and buff alos with mastitis in Dakahlia Governorate, Egypt. Journal Dairy Science, v. 98, p. 7450-7459, 2015.

EL-ASHKER, M.; GWIDAB, M.; MONECKEC,d,e, S.; EL-GOHARYB, F.; EHRICHTC, D.H., R.; ELSAYEDB, M.; AKINDUTIF, P.; EL-FATEHB, M.; MAURISCHATG, S. Antimicrobial resistance pattern and virulence profile of $S$. aureus isolated from household cattle and bufalo with mastitis in Egypt. Veterinary Microbiology, v. 240, 2020.

FACCIN, A.; SCHUCH, L.F.D.; SCHIAVON, D.B.A.; GONÇALVES, C.L.; MOTA, F. LESSA, L.F. Utilização do extrato hidroalcoólico de Schinus terebinthifolius Raddi na antissepsia do teto pré e pós ordenha em bovinos de leite. Ciência Animal Brasileira, v. 17, n. 1, p. 90-97, 2016.

FONSECA, L.F.L.; SANTOS, M.V. Qualidade do leite e controle de mastite. São Paulo : Lemos Editorial, 2000. 175P.

FREITAS, C.H.; GONCALVES, C.L.; MENDES, J.F.; OTERO, D.M., PEREIRA, D.M.; GONZALEZ, H.L. NASCENTE, P.S. Antimicrobial activity of fixed oil found in Brazil nuts and sunflower seeds against microorganisms isolated from bovine subclinical mastitis. African Journal of Microbiology Research. v.10, n.23, p.861-865.

FREITAS, C. H.; MENDES, J. F.; VILLARREAL, P. V.; SANTOS, P. R.; GONÇALVES, C. L.; . GONZALES, H.; NASCENTE, P. S. Identification and antimicrobial suceptibility profile of bacteria causing bovine mastitis from dairy farms in Pelotas, Rio Grande do Sul. Brazilian Journal of Biology, v. 78, n. 4, p. 661-666, 2018.

GALDINO, M. C.; DOMINGUES, P. F.; FERREIRA, B. L. S. A produção de leite orgânico e aspectos de segurança alimentar. Veterinária e Zootecnia, p. 490-501, 2012.

GIANNEECHINI, R.; CONCHA, C.; RIVERO, R.; DELUCCI, I.; LOPES, J.M. Occurrence of clinical and sub-clinical mastitis in dairy herds in the West Littoral Region in Uruguay. Acta Veterinaria Scandinavica, v. 43, n. 4, p. 1-10, 2002.

GUERREIRO, P.K.; MACHADO, M.R.; BRAGA, G.C.; GASPARINO, E.; FRANZENER, A.S.M. Qualidade microbiológica de leite em função de técnicas profiláticas no manejo de produção. Ciência e Agrotecnologia. v. 29, n. 1, p. 216 - 222, 2005.

HOGAN, J. S.; SMITH, K. L.; HOBLET, D. H.; TODHUNTER, D. A.; SCHOENBERGER, P. S.; HUESTON, W. D.; PRITCHARD, D. E.; BOWMAN, G. L.; HEIDER, L. E.; BROKETT, B. L.; CONRAD. H. R. Bacterial counts in bedding materials used on nine commercial dairies. Journal Dairy Science v. 72, p. 250-258. 1989b.

IKRAM, M.; INAMUL, $H$. Screening of medicinal plants for antimicrobial activities. Fitoterapia, v. 55, p. 62-64, 1984. 
IZZO, A. A.; BISCARDI, C. D.; FUSCO, G.; MASCOLO, D.; BORRELI, R.; CAPASSO, N.; FASULO, F.; AUTORE, F. Biological screening of Italian medicinal plants for antibacterial activity. Phytother Research v. 9, p. 281-286, 1995.

KORB, A.; BRAMBILLA, D. K.; TEIXEIRA, D. C.; RODRIGUES, R. M. Riscos para a saúde humana do uso de antibióticos na cadeia produtiva leiteira. Revista de Saúde Pública de Santa Catarina, v. 4, n. 1, p. 21-36, 2011.

LANGONI, H. Qualidade do leite: utopia sem um programa sério de monitoramento da ocorrência de mastite bovina. Pesquisa Veterinária Brasileira, v. 33, n. 5, p. 620-626, 2013.

LOPES, M. A.; DEMEU, F. A.; DA ROCHA, C. M. B. M.; DA COSTA, G. M.; FRANCO NETO, A.; DOS SANTOS, G. Avaliação do impacto econômico da mastite em rebanhos bovinos leiteiros. Arquivos do Instituto Biológico, v. 79, n. 4, p. 477-483, 2012.

LOZANO, C.; GHARSA, H.; BEN SLAMA, K.; ZARAZAGA, M.; TORRES, C.; Staphylococcus aureus in animals and food: methicillin resistance, prevalence, and population structure. A review in the African continent. Microorganisms, v. 4, p. 12, 2016.

MANZANERO-MEDINA, G. I.; FLORES-MARTÍNEZ, A.; SANDOVALZAPOTITLA, E.; BYE-BOETTLER, R. Etnobotánica de siete raíces medicinales en el Mercado de Sonora de la ciudad de México. Polibotánica, n. 27, p. 191-228, 2009.

MARIANO, F. A., FOLLY, M.M., TEIXEIRA, G.N., CARMO, L.S.; VIEIRA-DA-MOTTA, O. Produção de enterotoxinas por Staphylococcus isolados de leite de cabras do estado do Rio de Janeiro. Revista Brasileira de Ciência Veterinária, v. 14, n. 2, 2007.

MARTÍNEZ, N.; ALMAGUER, G.; VÁZQUEZ-ALVARADO, P.; FIGUEROA, A.; ZÚNIIGA, C.; HERNÁNDEZ-CERUELOS, A. Análisis fitoquímico de Jatropha dioica y determinación de su efecto antioxidante y quimioprotector sobre el potencial genotóxico de ciclofosfamida, daunorrubicina y metilmetanosulfonato evaluado mediante el ensayo cometa. Boletín Latinoamericano y del Caribe de Plantas Medicinales y Aromáticas, v. 13, n. 5, p. 437-457, 2014.

MEHMETI1, I.; BEHLUli, B.; MESTANI, M.; ADEMI, A.; NES, I. F.; DIEP, D. B. Antimicrobial resistance levels amongst staphylococci isolated from clinical cases of bovine mastitis in Kosovo. Journal Infect Dev Ctries, v. 10, n.10, p. 1081-1087, 2016.

MIDDLETON, J. R.; SAEMAN, A.; FOX, L. K.; LOMBARD, J.; HOGAN, J. S.; SMITH, K. L. The National Mastitis Council: a global organization for mastitis control and milk quality, 50 years and beyond. J. Mammary Gland Biology Neoplasia, v.19, p.241-251, 2014.

NEVES, E. L.; FUNCH, L. S.; VIANA, B. F. Comportamento fenológico de três espécies de Jatropha (Euphorbiaceae) da Caatinga, semi-árido do Brasil. Brazilian Journal of Botany, v. 33, n. 1, p. 155-166, 2010.

NEVES, E. L. das; MACHADO, I. C.; VIANA, B. F. Sistemas de polinização e de reprodução de três espécies de Jatropha (Euphorbiaceae) na Caatinga, semi-árido do Brasil. Brazilian Journal of Botany, v. 34, n. 4, p. 553-563, 2011. 
NASCIMENTO, G.G.F.; LOCATELLI, J.; FREITAS, P.C.; SILVA, G.L. Antibacterial activity of plant extracts and phytochemicals on antibiotic resistant bacteria Brazilian Journal of Microbiology, v.31, p.247-256, 2000.

NEVES, E. L. das; FUNCH, L. S.; VIANA, B. F. Comportamento fenológico de três espécies de Jatropha (Euphorbiaceae) da Caatinga, semi-árido do Brasil. Brazilian Journal of Botany, v. 33, n. 1, p. 155-166, 2010.

NEVES, E. L. das; MACHADO, I. C.; VIANA, B. F. Sistemas de polinização e de reprodução de três espécies de Jatropha (Euphorbiaceae) na Caatinga, semi-árido do Brasil. Brazilian Journal of Botany, v. 34, n. 4, p. 553-563, 2011.

OKOH, S.O., IWERIEBOR, B.C., OKOH, O.O., NWODO, U.U., OKOH, A.I. Antibacterial and Antioxidant Properties of the Leaves and Stem Essential Oils of Jatropha gossypifolia L. Biomed Research International v.2016, p.1-9, 2016.

OLIVEIRA S. G. D.; NASCENTE P. S.; ESCAREÑO J. J. H.; CARVALHO R. V.; PIVA E.; LUND, R. G. Evaluation of anti-Candida activity and cytoxicity of Jatropha dioica Cerv. extracts. African Journal of Microbiology Research, v. 7, n. 30, p. 3903-3907, 2013.

OLIVEIRA F.C.S., BARROS R.F.M., MOITA NETO J.M.. Plantas medicinais utilizadas em comunidades rurais de Oeiras, semiárido piauiense. Revista Brasileira Plantas Medicinais, v.12, n.3, p.282-301, 2010.

OLIVER, S.P. Frequency of isolation of environmental mastitis-causing pathogens and incidence of new intramammary infection during the nonlactating period. American Journal Veterinary Research. v.49, p.1789-1793, 1988.

PEREZ-ESCANDON, B.E., VILLAVICENCIO-NIETO, M.A., RAMIREZ-AGUIRRE, A. Lista de las plantas útiles del estado de Hidalgo Universidad Autónoma del Estado de Hidalgo, Centro de Investigaciones Biológicas 133 p., 2003.

PEIXOTO, A.L.P.; SILVA, M.A.; MORAIS, L.A.M.; SILVA F.R.; CARMO R.M.; LAGE, M.E. Influência do tipo de ordenha e do armazenamento do leite sobre a composição química, contagem de células somáticas e contagem bacteriana total. Revista do Instituto de Laticínios Cândido Tostes, v. 71, n. 1, p. 10-18, 2016.

PYÖR ÄLÄ, S.; TAPONEN, S. Coagulase-negative staphylococci-Emerging mastitis pathogens. Veterinary microbiology, v. 134, n. 1-2, p. 3-8, 2009.

RADOSTITS, O. M.; Leslie, K. E.; Fetrow, J. HerdHealth: Food Animal Production Medicine. 2nd ed. W.B. Saunders Company, Philadelphia, PA. 1994.

RAMPADARATH, S.; PUCHOOA, D.; RANGHOO-SANMUKHIYA, V. M. A comparison of polyphenolic content, antioxidant activity and insecticidal properties of Jatropha species and wild Ricinus communis L. found in Mauritius. Asian Pacific journal of tropical medicine, v. 7, p. S384-S390, 2014.

SANTOS M. V.; FONSECA L. F. L. Estratégias para Controle de Mastite e Melhoria da Qualidade do Leite. Editora Manole, Barueri. 314p. 2007. 
SANTOS, E.M.P.; BRITO, M.A.V.P.; LANGE, C.; BRITO, J.R.F.; CERQUEIRA, M.M.O.P. Streptococcus e gêneros relacionados como agentes etiológicos de mastite bovina Acta Scientiae Veterinariae. v.35, n.1, p.17-27, 2007.

SCHUCH, L. F. D.; WIEST, J. M.; COIMBRA, H. S.; PRESTES, L. S.; De TONI, L.; LEMOS, J. S. Cinética da atividade antibacteriana in vitro de extratos naturais frente a microrganismos relacionados à mastite bovina. Ciência Animal Brasileira, v. 9, n. 1, p. 161-169, 2008.

SILVA, N. M. A.; BASTOS, L.P.F.; OLIVEIRA, D.L.S.; OLIVEIRA, M.C.P.P.; FONSECA, L.M. Influence of somatic cell count and total bacterial counts of raw milk in cheese yield using small-scale methodology. Arquivos Brasileiros de Medicina Veterinária e Zootecnia, v. 64, n. 5, p. 1367- 1372, 2012.

SILVA, C. R.; FRÖHLICH, J. K.; OLIVEIRA, S. M.; CABREIRA, T. N.; ROSSATO, M. F.; TREVISAN, G.; FROEDER, A. L.; BOCHI, G. V.; MORESCO, R. N.; ATHAYDE, M. L. The antinociceptive and anti-inflammatory effects of the crude extract of Jatropha isabellei in a rat gout model. Journal Ethnopharmacology v. 145, p. 205-213, 2013.

SILVA-BELMARES, Y.; RIVAS-MORALES, C.; VIVEROS-VALDEZ, E.; de la CRUZGALICIA, M. G.;, CARRANZA-ROSALES, P. Antimicrobial and cytotoxic activities from Jatropha dioica roots. Pakistan Journal Biology Science, v. 17, n.5, p. 748-750, 2014.

SILVA-MARES, D.; TORRES-LÓPEZ, E.; RIVAS-ESTILLA, A. M.; CORDERO-PÉREZ, P.; WAKSMAN-MINSKY, N.; RIVAS-GALINDO, V. M. Plants from northeast Mexico with anti-HSV activity. Natural Products Communications, v. 8, n.3, p. 297-298, 2013.

SMITH, K.L.; HOGAN, J.S. Environmental mastitis. Veterinary Clinical North American Food Animal Practice v.9, p.489-98, 1993.

TIMMIS, L.L.; SCHULTZ, L.H. Dynamics and significance of coagulase-negative staphylococcal intramammary infections. Journal Dairy Science v.70, p.2648 -2657, 1987.

TITZE, I.; KRÖMKER, V. Antimicrobial Activity of a Phage Mixture and a Lactic Acid Bacterium against Staphylococcus aureus from Bovine Mastitis. Veterinary Science v. 7, p. $31,2020$.

VARGAS-SEGURA, A. I.; SILVA-BELMARES, S. Y.; SEGURA-CENICEROS, E. P.; ASCACIO-VALDÉS, J. A.; MÉNDEZ-GONZÁLEZ, L.; ILYINA, A. Screening and characterization of medicinal plants extracts with bactericidal activity against Streptococcus mutans Natural Prod. Research v.8, p. 1-5.

VASCONCELLOS, S. A.; ITO, F. H. Principais zoonoses transmitidas pelo leite. Atualização. Revista de Educação Continuada em Medicina Veterinária e Zootecnia do CRMV-SP, v. 9, n. 1, p. 32-37, 2011.

VISSIO, C.; MELLA, A.; AMESTICA, L.; PO M. Noninferiority study evaluating the efficacy of a teat disinfectant containing copper and zinc for prevention of naturally occurring intramammary infections in an automatic milking system. Journal Dairy Science v. 103, p. 1776-1784, 2020. 
ZADOKS, R. N. GILLESPIE, B., BARKEMA, H., SAMPIMON, O., OLIVER, S., \& SCHUKKEN, Y. Clinical, epidemiological and molecular characteristics of Streptococcus uberis infections in dairy herds. Epidemiology \& Infection, v. 130, n. 2, p. 335-349, 2003.

ZANETTE, E.; SCAPIN, D.; ROSSI, E.M. Suscetibilidade antimicrobiana de Staphylococcus aureus isolados de amostras de leite de bovinos com suspeita de mastite. UNOESC \& Ciência ACBS, v. 1, n. 1, p. 65-70, 2010

WHO - Word Health Statistics, 2015. 